\title{
Transplante Ortotópico de Coração: Experiência de 27 Casos
}

Noedir A. G. STOLF*, Alfredo I. FIORELLI*, Pedro Carlos P. LEMOS*, Pablo M. A. POMERANTZEFF*, Fábio B. JATENE*, José Otávio C. AULER JUNIOR*, Jorge M. S. PASCUAL*, Edmar BOCCHI*, Lourdes HIGUSHI, Giovanni BELLOTTII*, Fulvio PILEGGI*, Adib D. JATENE*

RBCCV 44205-31

STOLF, N. A. G.; FIORELLI, A. I.; LEMOS, P. C. P.; POMERANTZEFF, P. M. A.; JATENE, F. B.; AULER JÚNIOR, J. O. C.; PASCUAL, J. M. S.; BOCCHI, E.; HIGUSHI, L.; BELLOTTI, G.; PILEGGI, F.; JATENE, A. D. - Transplante ortotópico de coração: experiência de 27 casos. Rev. Bras. Cir. Cardiovasc. 2(2): 115-120, 1987.

RESUMO: Os autores apresentam a experiência de 27 pacientes portadores de cardiomiopatia em fase terminal, que foram submetidos a transplante cardiaco ortotópico, no periodo de março de 1985 a fevereiro de 1987 (23 meses), no Instituto do Coração do Hospital das Clínicas da Faculdade de Medicina da Universidade de São Paulo. As principais indicaçōes foram cardiomiopatia dilatada em 12 casos $(44,5 \%)$. isquêmica em 10 casos $(37,08 \%)$, chagásica em 4 casos $(14,8 \%)$ e reumática em 1 caso $(3,7 \%)$. A mortalidade imediata foi de 3,7\% (1 caso), por falência do enxerto, e a tardia, de 7,4\% (2 casos), por rejeição e endocardite. Atualmente, 19 pacientes $(70,3 \%)$ encontram-se em classe funcional I, 1 paciente $(3,7 \%)$ em classe funcional II e $4(14,8 \%)$ em pós-operatório recente, embora já realizando exercício programado.

DESCRITORES: transplante cardiaco, ortotópico.

\section{INTRODUÇÃO}

O transplante cardíaco, ao lado de modificar a evolução da história natural da cardiomiopatia terminal, oferece melhor qualidade de vida aos pacientes. Estudos realizados pelo grupo de Stanford ${ }^{2}$ demonstram que pacientes não operados, com indicação para transplante de coração, apresentam sobrevida média de três a seis meses. O transplante tem oferecido, a esses pacientes, sobrevida de $80-85$ e $60-65 \%$, no primeiro e quinto ano após a operação, respectivamente ${ }^{6}$.

Com a introdução da ciclosporina, em $1980^{4}$, na terapêutica imunossupressora, a severidade dos episódios de rejeição e infecção diminuiu e o seu controle tornou-se mais fácil. Estes fatores, entre outros, contribuíram para aumentar o interesse pelo transplante e a multiplicação dos centros que o realizam.
A partir de 1985, no Instituto do Coraçāo do Hospital das Clínicas da Faculdade de Medicina da Universidade de São Paulo, o programa de transplante cardiaco foi reativado, sendo realizadas 27 operaçōes. O presente estudo tem por finalidade apresentar essa experiência inicial.

\section{CASUISTICA}

No período de março de 1985, a fevereiro de 1987 (23 meses), 27 pacientes, com idade variando entre 16 a 55 anos (média de 39,9 anos), sendo 24 do sexo masculino, foram submetidos a transplante cardíaco ortotópico. Quanto à cor, $21((77,8 \%)$ eram de cor branca; $4(14,8 \%)$, parda e $2(7,4 \%)$, amarela. Os critérios de indicaçāo cirúrgica foram: cardiomiopatia dilatada em 12

Trabalho realizado no Instituto do Coração do Hospital das Clínicas da Faculdade de Medicina da Universidade de São Paulo. Sâo Paulo, SP. Brasil.

Apresentado ao 14: Congresso Nacional de Cirurgia Cardiaca, Salvador BA, 27 e 28 de março, 1987.

- Do Instituto do Coração do Hospital das Clinicas da Faculdade de Medicina da Universidade de São Paulo.

Endereço para separatas: Noedir Stolf. Av. Dr. Enéas Carvalho de Aguiar, 44. Divisão Cirúrgica. 05403 São Paulo, SP, Brasil. 
STOLF. N. A. G.: FIORELLI. A. I.: LEMOS. P. C. P.: POMERANTZEFF. P. M. A. JATENE. F. B.: AULER JUNIOR. J. O C. PASCUAL. J. M. S.: BOCCHI, E.: HIGUSHI. L.: BELLOTTI. G.: PILEGGI. F.: JATENE. A. D. - Transplante ortotopico de coração: experiéncia de 27 casos. Rev. Bras. Cir. Cardiovasc. 2(2):115-120. 1987.

casos $(44,5 \%)$; isquêmica em 10 casos $(37,0 \%)$, chagásica em 4 casos $(14,8 \%)$ e reumática em 1 caso $(3,7 \%)$. Quatro pacientes $(14,8 \%)$ apresentavam operações anteriores: em $2(7,4 \%)$, implante de marcapasso endocavitário; em $1(3,7 \%)$ revascularização do miocárdio e em outro $(3,7 \%)$, duas operaçōes para substituição valvar (mitral e aórtica).

Todos encontravam-se em classe funcional IV (NYHA), exceto 1, que estava em classe I e era produtor de arritmia refratária ao tratamento clínico. Nesta série, no periodo pré-operatório, 6 pacientes $(22,2 \%)$ apresentaram embolia pulmonar e $5(18,5 \%)$ permaneceram internados em unidade de tratamento intensivo, por choque cardiogênico prolongado.

Os pacientes foram submetidos a extensa avaliação clínica e psicológica e os critérios de seleção dos receptores foram os classicamente aceitos ${ }^{5}$.

Nos pacientes doadores, o diagnóstico clínico de morte cerebral foi confirmado por eletroencefalograma e/ou ausência de circulação cerebral determinada na arteriografia. A Tabela 1 apresenta as principais características da população de pacientes doadores.

TABELA 1

CARACTERISTICAS DO PACIENTE DOADOR

\begin{tabular}{|c|c|c|c|c|}
\hline Sexo Masculino & & - & 25 & $92,5 \%$ \\
\hline Idade & $(17-37 A)$ & & & $29,9 \mathrm{~A}$ \\
\hline Diagnóstico de & EEG & - & 5 & $18,5 \%$ \\
\hline \multicolumn{4}{|l|}{ Causa de óbito } & $85,1 \%$ \\
\hline \multicolumn{2}{|c|}{ Contusāo de crâneo } & - & 12 & $44,4 \%$ \\
\hline \multicolumn{2}{|c|}{ Ferimento por arma de fogo } & - & 6 & $22,2 \%$ \\
\hline \multicolumn{2}{|c|}{ AVCH } & - & 1 & $3,7 \%$ \\
\hline \multicolumn{5}{|c|}{ Retirada de outros órgāos } \\
\hline \multicolumn{2}{|l|}{ Rins } & :- & 10 & $37,0 \%$ \\
\hline \multicolumn{2}{|l|}{ Córnea } & - & 9 & $33,3 \%$ \\
\hline \multirow{2}{*}{\multicolumn{2}{|c|}{$\begin{array}{l}\text { Figado } \\
\text { Isquemia miocárdica }\end{array}$}} & - & 1 & $3,7 \%$ \\
\hline & & & & \\
\hline (60 a $230 \mathrm{~min})$ & & - & 91,6 & $\min$ \\
\hline
\end{tabular}

O esquema de imunossupressão, adotado inicialmente em 10 pacientes, incluiu ciclosporina com dose inicial de $15 \mathrm{mg} / \mathrm{Kg}$ de peso e manutenção de níveis no sangue total de 800 a $1200 \mathrm{mg} / \mathrm{ml}$, associado a metilprednisolona com $1,0 \mathrm{Kg}$ no transoperatório, até o segundo dia de pós-operatório, e manutenção com prednisona $1,0 \mathrm{mg} / \mathrm{Kg}$ de peso, diariamente. Um paciente recebeu ciclosporina azatioprina, por ser diabético. Os demais pacientes receberam ciclosporina, azatioprina 1,5 a 2,0 $\mathrm{mg} / \mathrm{Kg}$ de peso e corticóide. A dose de ciclosporina, nesse esquema tríplice, foi reduzida para 5 a $10 \mathrm{mg} / \mathrm{Kg}$ de peso. Atualmente, todos os pacientes, tardiamente, encontram-se recebendo esquema tríplice.

\section{RESULTADOS}

No periodo analisado, 3 pacientes morreram, sendo 1 no pós-operatório imediato $(3,7 \%)$, por falência do enxerto, e 2 no periodo tardio $(7,4 \%)$, por endocardite e rejeição intratável.

No Gráfico 1, é apresentada a incidência de episódios de rejeições, observados em biópsias endomiocárdicas realizadas de rotina e em função da evoluçāo. Nota-se que o número de pacientes com episódios de rejeiçāo e o número de biópsias diminuiram, progressivamente, no tempo. $\mathrm{O}$ Gráfico 2 demonstra que não houve diferença significativa no número de episódios de rejeição, em biópsias, nos pacientes que receberam ou não azatioprina, na terapêutica imunodepressora.

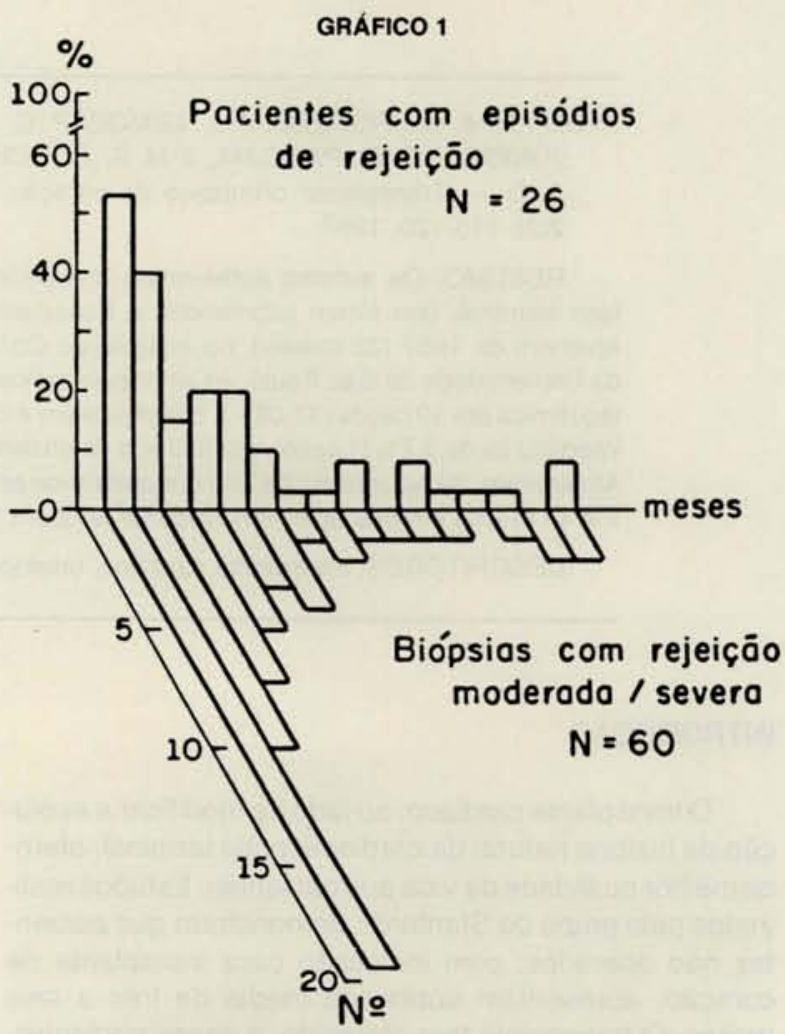

Gráfico 1: Nota-se que o número de biópsias com rejeição moderada e severa e dos pacientes com episódios de rejeição não săo maiores nos primeiros meses pós transplante.

Das biópsias endomiocárdicas programadas, $50 \%$ apresentavam evidências de rejeição. Os diferentes tipos histológicos de rejeição observados foram: discreta, 125 $(55,8 \%)$; moderada, $90(40,2 \%)$ e severa, $9(4,0 \%)$. Os niveis de ciclosporina no sangue, nos episódios de rejeição, são apresentados no Gráfico 3.

As principais complicações que ocorreram no período tardio são apresentadas na Tabela 2. No Gráfico 4 pode-se notar que a incidência de processos infecciosos é maior nos primeiros meses de evolução. 
GRÁFICO 2

\section{EPISÓdIOS DE REJEIÇÃO EM BIÓPSIAS ANTES E APOS AZATIOPRINA}

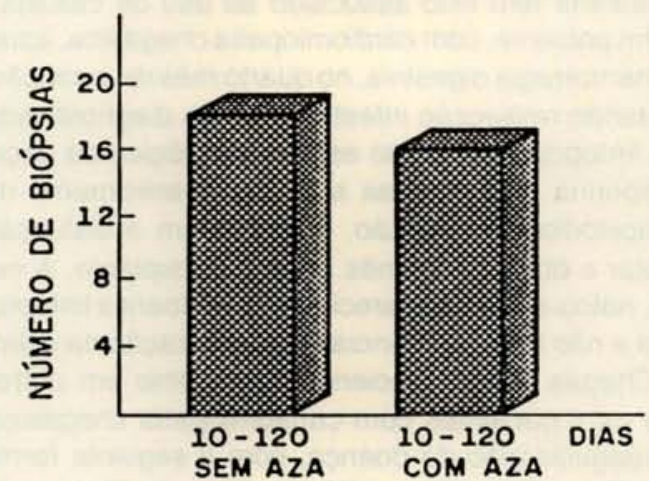

Gráfico 2: Mostra que não houve diferenças no numero de rejeiçōes nas biópsias antes e após o uso de azatioprina.

GRÁFICO 3

\section{NIVEIS DE CICLOSPORINA NO EPISÓDIO DE REJEIÇÃO}

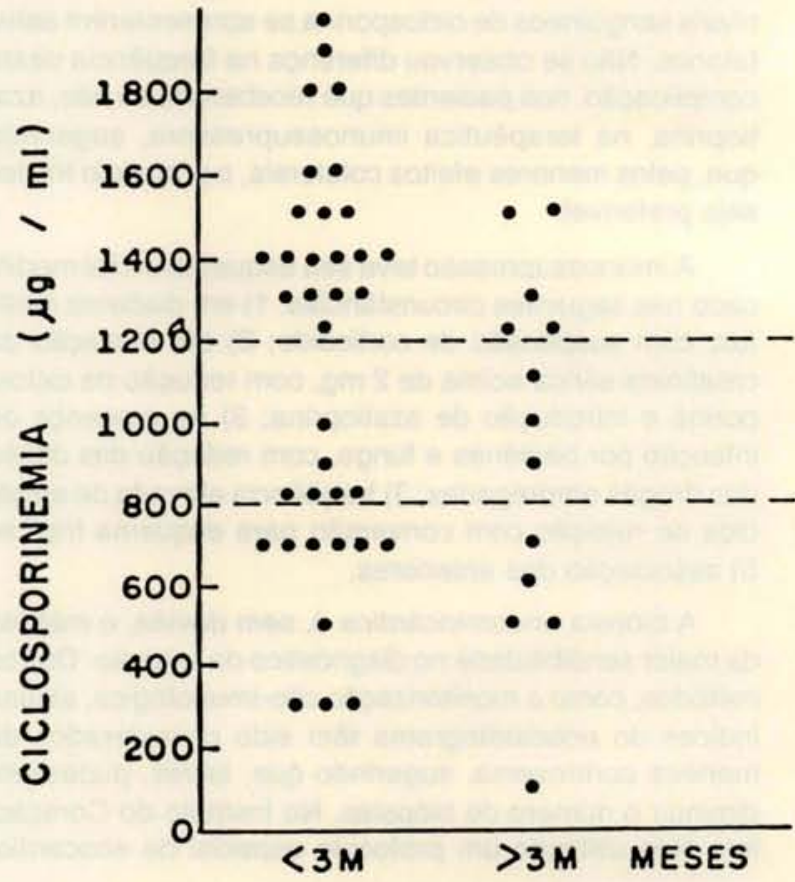

Gráfico 3: Neste gráfico sâo apresentados os niveis de ciclosporina nos episódios de rejeiçăo, antes e após o $3^{\circ}$. mês de evolução pós trans. plante.

São 24 os pacientes sobreviventes. Quatro estão em pós-operatório mais recente, porém já com exercício programado em bicicleta, sem limitaçāo física (classe funcional I); 19 estão em pós-operatório tardio, em classe funcional I e 1 paciente, que apresenta aterosclerose coronária, encontra-se em classe funcional II.

DE CORACAO - 27 CASOS
INFECCAO

TRANSPLANTE DE CORACAO - 27 CASOS
INFECCAO

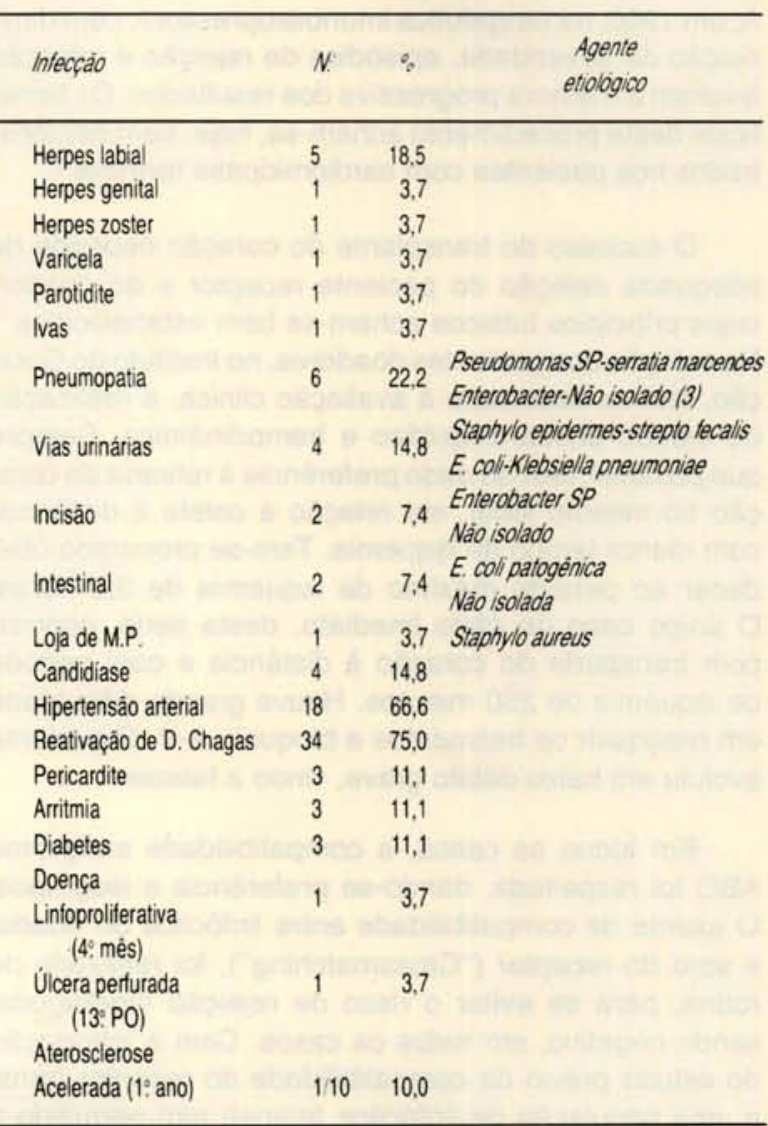

GRÁFICO 4

TRANSPLANTE CARDÍACO - 27 cosos

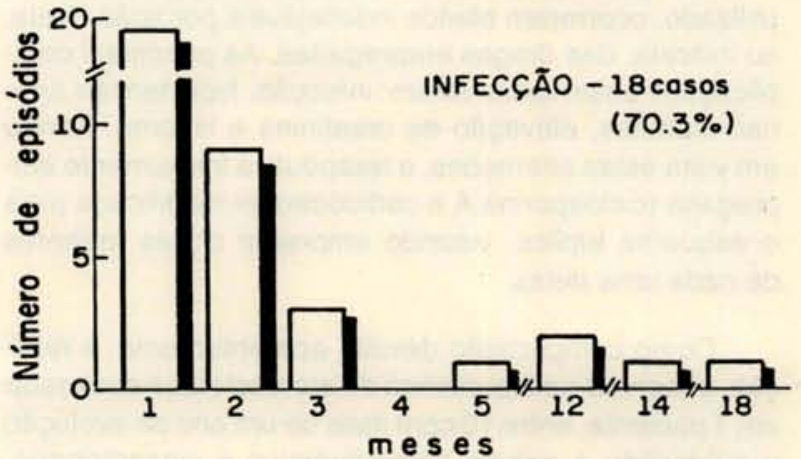

Gráfico 4: Número de episódios de infecção no primeiro trimestre de pós transplante. 
STOLF, N. A. G.; FIORELLI, A. I.: LEMOS, P. C. P.: POMERANTZEFF. P. M. A : JATENE. F. B.: AULER JÜNIOR, J. O. C.: PASCUAL, J. M. S.; BOCCHI, E.; HIGUSHI, L.; BELLOTTI, G.: PILEGGI, F.: JATENE. A. D. - Transplante ortotopico de coração: experiência de 27 casos. Rev. Bras. Cir. CardiovasC., 2(2):115-120, 1987.

\section{DISCUSSÃO}

A partir do primeiro transplante cardiaco humano, realizado, com sucesso, por Barnard, em 1967, o método ganhou grande difusāo, em todo o mundo. A maioria dos centros, no entanto, interrompeu seus programas, devido à alta morbidade e mortalidade, devidas a rejeição e infecção. Uma série de avanços, no campo do transplante cardiaco, inclusive a introdução da ciclosporina A, em 1980, na terapêutica imunossupressora, com diminuiçāo da severidade, episódios de rejeiçāo e infecçāo levaram à melhora progressiva dos resultados. Os benefícios deste procedimento acham-se, hoje, bem demonstrados nos pacientes com cardiomiopatia terminal ${ }^{2}$.

O sucesso do transplante do coração depende de adequada seleção do paciente receptor e do doador, cujos princípios básicos acham-se bem estabelecidos ${ }^{5}$. Na seleção dos pacientes doadores, no Instituto do Coração, tem-se associado à avaliação clínica, a realização de estudo ecocardiográfico e hemodinâmico. Sempre que possivel, tem-se dado preferência à retirada do coração no mesmo local, em relação à coleta à distância, com menor tempo de isquemia. Tem-se procurado obedecer ao periodo máximo de isquemia de 3,5 horas. O único caso de óbito imediato, desta série, ocorreu com transporte do coração à distância e com período de isquemia de 230 minutos. Houve grande dificuldade em readquirir os batimentos e bloqueio $\mathrm{A}-\mathrm{V}$. O paciente evoluiu em baixo débito grave, vindo a falecer.

Em todos os casos, a compatibilidade sangüinea $A B O$ foi respeitada, dando-se preferência a isogrupos. O exame de compatibilidade entre linfócitos do doador e soro do receptor ("Crossmatching"), foi realizado de rotina, para se evitar o risco de rejeição hiperaguda, sendo negativo, em todos os casos. Com a introdução do estudo prévio de compatibilidade do receptor frente a uma população de linfócitos (painel) tem permitido a realização do transplante sem aguardar o resultado do "Crossmatching") '. Esse procedimento tem especial importância na procura de órgãos à distância.

Em qualquer que seja o esquema imunossupressor utilizado, ocorreram efeitos indesejáveis por ação direta, ou indireta, das drogas empregadas. As principais complicações observadas foram: infecção, hipertensão arterial, diabetes, elevação de creatinina e linfoma. Tendo em vista estas alteraçōes, a terapêutica inicialmente empregada (ciclosporina A e corticóide) foi modificada para o esquema tríplice, visando empregar doses menores de cada uma delas.

Como complicação devida, aparentemente, à rejeição, observou-se a presença de aterosclerose acelerada em 1 paciente, entre $10 \mathrm{com}$ mais de um ano de evolução e submetido a estudo hemodinâmico e cinecoronariográfico de controle. Este efeito, nas séries com ciclosporina, tem sido descrito em receptores com maior número de remeiçōes ${ }^{7}$. Esse paciente, em 14 biópsias realizadas nesse período, apresentou três episódios de rejeição leve, 4 de rejeição moderada e 1 de severa, tendo recebido várias pulsoterapias.

O linfoma tem sido associado ao uso de ciclosporina ${ }^{3}$. Um paciente, com cardiomiopatia chagásica, apresentou hemorragia digestiva, no quarto mês de evolução, necessitando ressecção intestinal, sendo diagnosticada doença linfoproliferativa, ao estudo histológico da peça. A ciclosporina foi suspensa e houve aparecimento de vários episódios de rejeição, que levaram a disfunção ventricular e óbito, no 8 . mês após o transplante. A necrópsia, notou-se o desaparecimento de doença linfoproliferativa e nāo havia evidências de agudizaçāo da doença de Chagas. Nesse paciente, bem como em outros 2 , entre os 4 pacientes com cardiomiopatia chagásica, houve reagudização da doença, com a seguinte forma clínica: febre, miocardite e nódulos de paniculite em abdome e tórax, ou membros inferiores, cuja biópsia evidenciou presença de formas amastigotas do Trypanosoma cruzi. Todos receberam benzonidazol $10 \mathrm{mg} / \mathrm{Kg} /$ dia), durante 60 dias, com regressão do quadro clínico, em dois a quatro dias.

Com relaçāo aos processos infecciosos, nota-se, também, maior incidência nos primeiros meses de evolução, ocorrendo, posteriormente, de forma isolada. Do mesmo modo, a freqüência de episódios de rejeição foi maior, nos primeiros meses de evolução, apesar dos niveis sangüineos de ciclosporina se apresentarem satisfatórios. Não se observou diferença na freqüência desta complicação, nos pacientes que receberam, ou não, azatioprina, na terapêutica imunossupressora, sugerindo que, pelos menores efeitos colaterais, o protocolo tríplice seja preferivel.

A imunossupressão teve seu esquema inicial modificado nas seguintes circunstâncias: 1) em diabetes mellitus, com suspensāo de corticóide; 2) em elevação da creatinina sérica acima de $2 \mathrm{mg}$, com redução da ciclosporina e introdução de azatioprina; 3) na presença de infecção por bactérias e fungo, com redução das doses das drogas empregadas; 3 ) freqüência elevada de episódios de rejeição com conversão para esquema tríplice; 5) associação dos anteriores.

A biópsia endomiocárdica é, sem dúvida, o método de maior sensibilidade no diagnóstico da rejeição. Outros métodos, como a monitorização cito-imunológica, alguns índices do ecocardiograma têm sido considerados de maneira controversa, sugerindo que, talvez, pudessem diminuir o número de biópsias. No Instituto do Coração, tem sido utilizado um protocolo especial de ecocardio-

\footnotetext{
- MENEGUetti, S. C.; SOARES. J.; BUChPINGUEl, C. A.;BEllotti, G.; BOCCHI, E.; HIGUCHI, M. L.; STOLF. N. A. G.; HIRONAKA F.; PILEGGI, F.; JATENE, A. D.; CAMARGO, E. - Gallium-67 scintigraphy on heart transplantation: correlation with endomyocardial biopsy. Apresentado ao IV World Congress of the Federation of Nuclear Medicine and Biology. Buenos Aires, Argentina, 1986
} 
STOLF. N. A. G.: FIORELli. A. I.: LEMOS. P. C. P.: POMERANTZEFF. P. M. A : JATENE. F. B.: AULER JÚNIOR. J. O. C.: PASCUAL. J. M. S.: BOCCHI. E.: HIGUSHI. L.: BELLOTTI. G.: PILEGGI. F.: JATENE. A. D. - Transplante ortotopico de coração: experiência de 27 casos. Rev. Bras. Cir. Cardiovasc. 2(2):115-120. 1987.

grama e mapeamento com Gallium*. Este último, especialmente, parece apresentar sensibilidade e especificidade altas.

Quanto ao resultado funcional, no periodo analisado, 24 pacientes $(88,8 \%)$ portadores de miocardiopatia terminal encontram-se vivos. Destes, 4 pacientes estão em pós-operatório recente, 19 em classe funcional I $(70,3 \%)$ e $1(3,7 \%)$ em classe funcional II, sendo que a maioria retornou ao trabalho. Estes dados sugerem que essa experiência inicial apresenta os altos índices de sobrevida referidos na literatura ${ }^{1}$ e que têm permitido prolongar a vida e obter excelente reabilitação funcional aos pacientes transplantados.

RBCCV 44205-31

STOLF, N. A. G.: FIORELLI, A. I.; LEMOS, P. C. P.; POMERANTZEFF, P. M. A.; JATENE, F. B.; AULER JÚNIOR, J. O. C.: PASCUAL, J. M. S.; BOCCHI, E.; HIGUSHI, L.; BELLOTTI, G.; PILEGGI, F.; JATENE. A. D. - Orthotopic heart transplantation: experience with 27 cases. Rev. Bras. Cir. CardiovasC. 2(2) $115-120,1987$

ABSTRACT: The authors present the innitial experience with 27 patients, submitted to orthotopic heart transplantation, during the period of 23 months (march 85 to february 87 ), at the Heart Institute. University of São Paulo Medical School. Indications were idiopathic cardiomiopathy in 12 cases $(44.5 \%)$, ischemic cardiomiopathy in 10 cases $(37 \%)$. Chagas' cardiomiopathy in 4 cases $(14.8 \%)$ and rheumatic heart valve disease in 1 case $(37 \%)$. The early mortality was $37 \%$ (1 case), caused by inespecific graft failure long distance hearvesting and the late mortality was $7.4 \%$ ( 2 cases), caused by rejection and infective endocarditis. The 24 surviving patients were $(70.3 \%)$ in NYHA class I, 1 patient $(37 \%)$ is in functional class II and 4 patients are in early post-operative period.

DESCRIPTORS: heart transplantation, orthotopic.

\section{REFERÊNCIAS BIBLIOGRÁFICAS}

1 ANDERSON, R. W.; ELICK, B.; ASCHER, N.; SIMONS, R. L. - Cardiac transplantation without a prospective crossmatch. Transp. Proc., 37 (1): 209-211, 1985.

2 JAMIESON, S. W.; OYER, P. E.; PEITZ, B. A.; BAUM GARTNER, W. A.; BIEGER, C. P.; STINSON, E. B.: SHUMWAY, N. E. - Cardiac transplantation at Stanford. J. Heart Transpl., 4 (1): 86-91, 1985.

3 LYMPHOMA in organ transplant recipients - Lancet, 1 (8377): 601-603, 1984

4 OYER, P. E.; STINSON, E. B.; JAMIESON, S. W.; HUNT, S.: REITZ, B. A.; BIEBER, C. P.; SCHOEDER, J.; BILLINGHAM, M.; SHUMWAY, N. E. - One year experience with cyclosporine $\mathrm{A}$ in clinical heart transplantation. Heart Transplant., 1 (4): 285-290, 1982.

5 OYER, P. E.; STINSON, E. B.: SHUMWAY, N. E. - Present and future of cardiac transplantation. Ann. Clin. Res., 13: 318-326, 1981.

6 SOLIS, E. \& KAYE, M. P. - The registry of the International Society of Heart Transplantation: third official report. J. Heart Transpl., 5 (1): 2-5, 1986.

7 ZUSMAN, D. R.; STINSON, E. B.; OYER, P. E.; BALDWIN J. C.; JAMIESON, S. W.; Mc GREGOR, C. G.; HUNT, S. A.; SCHOEDER, J. S.; SHUMWAY, N. E. - Determinants of accelerated graft atherosclerosis in ventional and cyclosporine treated heart transplant recepients. J. Heart Transpl., 4 (6): 587, 1985

\section{Discussão}

PROF. E. J. ZERBINI

São Paulo, SP

Inicialmente, desejo manifestar meus cumprimentos aos autores, pela excelente apresentação da maior experiência com transplante cardiaco no País e com os excelentes resultados conseguidos. Minhas observações apenas visam provocar as respostas do Dr. Noedir sobre alguns pormenores, aumentando nossos conhecimentos sobre o problema. 1) Os critérios sobre a indicação foram enriquecidos com o transplante na doença de Chagas. Gostaria de mencionar a impropriedade do termo cardiomiopatia dilatada, que é um diagnóstico anátomo-funcional, ao passo que todos os outros são diagnósticos etiológicos. Talvez a expressāo cardiomiopatia de causa não conhecida fosse mais própria, pois a cardiomiopatia chagásica, por exemplo, é a melhor demonstração de uma cardiomiopatia dilatada. 2) A Tabela 2 informa sobre as complicaçōes, mas não menciona a freqüência da elevação da creatinina e a insuficiência renal, que é um problema polêmico, com o emprego da ciclosporina. Solicitamos os comentários do Dr. Noedir, neste campo. 3) $O$ trabalho deixa a impressão de que os doentes chagásicos não foram tratados com benzonidazol antes da realização do transplante. Poderia comentar este termo também polêmico? 4) No Gráfico 3, observamos que 25 pacientes permaneceram com níveis tóxicos de ciclosporina, acima de 1200 nanogramas nos episódios de rejeição. Nove pacientes apresentaram níveis satisfa- 
tórios, entre 800 e 1200 nanogramas. Quinze pacientes apresentavam niveis subterapêuticos. Perguntamos se estes niveis de ciclosporinemia não teriam relação com a freqüência dos episódios de rejeiçāo enumerados no gráfico 1? 5) Temos evitado o emprego dos corticóides, nos nossos casos, e estamos satisfeitos. Somente empregamos corticóides durante o transplante e durante os episódios da rejeição com a pulsoterapia. Esta conduta parece satisfatória, especialmente nos pacientes chagásicos. O primeiro doente chagásico, transplantado no dia 3 de junho de 1985, no nosso Serviço, teve uma excelente evolução, sem reativação de seu processo chagásico e continua com xenodiagnóstico negativo. Porque razão adicionar corticóides na terapêutica dos chagásicos, a não ser durante os episódios de rejeição? 6) Não foi comentado o problema da idade mínima e máxima nas indicaçōes e, penso, que todos gostariam de conhecer a opiniāo do Dr. Noedir. 7) Seis pacientes apresentaram embolia pulmonar no pré-operatório $(22,2 \%)$. Quais foram os estudos realizados para a decisão da indicação do transplante, nesses doentes. As unidades de resistência pulmonar têm valor decisivo para contra-indicar o transplante? 8) Qual é a opiniāo do Dr. Noedir sobre o diagnóstico clínico, não invasivo, da rejeição baseado no ecocardiograma, na monitorização imunológica e outros dados. Esses procedimentos não invasivos poderiam evitar as incômodas e trabalhosas biópsias do coração após o transplante?

\section{DR. STOLF}

(Encerrando)

Vamos procurar responder às questōes levantadas pelo Prof. Zerbini, de maneira suscinta: 1) Em relaçāo ao termo cardiomiopatia dilatada, por nós utilizado, acreditamos que ele é mais descritivo do que etiológico, porém consideramos que ele ainda é o mais apropriado para descrever esse grupo de miocardiopatias, uma vez que o termo "de causa desconhecida, ou idiopática" admitiria que não é possivel determiná-la e, em alguns deles, ela pode ser suspeitada. 2) Realmente, a nefroto- xidade é uma das mais importantes complicações decorrentes do uso da ciclosporina. No pós operatório imediato, todos os pacientes tiveram algum grau de elevação da creatinina sérica, com normalizaçăo após 10 a 15 dias. Após os 3 meses, ocorreram elevaçōes da creatinina, em graus variáveis, na maior parte dos pacientes. 3) Realmente, um paciente chagásico teve um tratamento prévio incompleto, antes de chegar ao Serviço; os demais, quando admitidos, tinham condição tão precária, que não suportaram o tratamento. 4) Realmente, os niveis sangüineos tiveram grande variação que foram ajustados segundo o comportamento do paciente. Não houve relação em níveis sangüineos e ocorrência de episódios de rejeição. 5) Em relação à necessidade, ou não, de agregar corticóide ao esquema de imunossupressão, é uma controvérsia em curso. Nós acreditamos que o corticóide em dose baixa não predispōe à reativação do Chagas, mais do que outras drogas. A pulsoterapia de corticóide, por outro lado, consideramos que possa ser mais inconveniente. 6) Consideramos que a literatura tem demonstrado que as crianças, e mesmo os neonatos, sāo candidatos satisfatórios ao transplante. Quanto aos limites superiores, consideramos que a idade ideal está abaixo dos 55 anos; porém, entre 55 e 60 anos, podemos obter bons resultados e, mesmo em condiçōes especiais, após os 60 anos. 7) A embolia pulmonar não resolvida, ou com menos de 2 a 3 meses, é uma contra-indicação. O Dr. Yacoub tem realizado transplante na vigência de infarto de pulmão, porém com morbidade aumentada. Se não houver infarto e a avaliação hemodinâmica mostrar resistência em niveis adequados, consideramos que a embolia não deve retardar o transplante. 8) O que nós verificamos é que todos os métodos não invasivos propostos para diagnóstico de rejeição têm sensibilidade e especificidade limitadas e conseguem, quando muito, diminuir o número de biópsias Quanto à ecocardiografia, os parâmetros convencionais não têm maior valor. O tempo de relaxamento isovolúmico, que alguns autores têm mostrado de algum valor, não tem confirmado a sua contribuição, na nossa experiência. Agradeço os comentários, pelas suas observaçōes, e a oportunidade de expressar idéias adicionais sobre $o$ assunto. 